\title{
Local authorities' Attitude Towards People with Mental Illness in Musanze District, Rwanda
}

\author{
Vedaste Baziga1*, Augustin Gasovya ${ }^{1}$, Fauste Uwingabire ${ }^{2}$
}

${ }^{1}$ School of Nursing and Midwifery, Mental Health Nursing, College of Medicine and Health Sciences, University of Rwanda

${ }^{2}$ School of Nursing and Midwifery, General Nursing, College of Medicine and Health Sciences, University of Rwanda

*Corresponding author: School of Nursing and Midwifery, Mental Health Nursing, College of Medicine and Health Sciences, University of Rwanda, Remera Campus, KG 11 Ave, 47, Kigali, Rwanda. Email: vedastebaziga2@gmail.com

\begin{abstract}
Introduction

Mental illnesses (MIs) are currently contributing to the worldwide burden of disease and they are among 10 main causes of disability on worldwide. In addition, mental Health care users are among the people most stigmatized by the general population which includes local leaders.

\section{Methods}

The design used for conducting this study was quantitative and cross-sectional survey and the study was conducted in Muhoza sector of Musanze District in Rwanda. The tool used to correct data was self-report questionnaire that included socio-demographic variables (gender, age, experience and level of education), level of contact scale and community attitudes towards mental illness - Swedish version (CAMI-S). In this study self-report questionnaire was provided to the local authorities in Muhoza sector ( $\mathrm{n}=123, \mathrm{~N}=174)$. Data analysis was done using a statistical package for social sciences (SPSS) version 22.
\end{abstract}

\section{Results}

Findings from the current study revealed negative stereotypical attitudes among local authorities towards people with mental illness. The participants' total score on the CAMI-S was ranging between $24 \%$ and $81 \%$. In addition, the study revealed some contradictions and neutral responses. Less negative stereotypical attitudes were found among participants who have university and secondary education levels than participants with primary education and those who have not completed primary school. In addition, participants with more experience in local government system reflected less negative stereotypical attitudes than participants who are less experienced in local government system. This study showed a negative correlation between level of contact and community attitudes towards mental illness.

\section{Conclusion}

Local authorities in a selected sector of Musanze District, hold negative stereotypical attitudes towards people with mental disorders. However, the extent of contradiction within participant responses suggests social desirability bias. Also, there is association between negative stereotypical attitudes and the level of education and experience. Finally, the results suggest that familiarity has a mediating effect on negative stereotypical attitudes.

Rwanda J Med Health Sci 2019;2(3):235-244.

Key words: Local authorities, mental illness, negative stereotypical attitudes, familiarity, sector

\section{Introduction}

Literature highlights characteristics of mental illness which include behavioural or psychological symptoms which could be associated with distress and disability or with an important loss of independence.[1] Mental illnesses and drug abuse are important causes of disability worldwide. The global prevalence of mental illnesses is estimated at $4 \%$ to $26 \%$ globally.[2]

,The prevalence will increase up to $23 \%$ in developed countries.[2,3] This issue of high prevalence of mental illness is stressed to be complicated by stigma and discrimination in regards to persons with a mental illness.
Stigma towards persons with mental illness is considered as a barrier to help seeking, full recovery and rehabilitation for persons in need of mental health services. [4]

To improve the quality of care provided to persons with mental illness, the integration of mental health services in general health care facilities was recommended by the World Health Organization. Such integration is argued to contribute in reduction of mental health related problems which currently are considered as burden. [5] This integration has been considered by the Government of Rwanda due to the fact that genocide against Tutsi in1994 has had negative impact on the mental health of Rwandans. 
The Rwandan Ministry of Health highlights enormous trauma related psychological and mental problems which affect negatively Rwandan mental health services. [6] To face mental health problems associated with the genocide, perpetrated against the Tutsis, the Ministry of Health in Rwanda started to integrate mental health from the community level up to referral level. Success of this integration at community level would rely on local authorities as long as they are coordinating all activities requested by the central government at the community setting including health related activities undertaken at community level. $[7,8]$

For such integration, the Rwandan Ministry of Health acknowledged nurses at all levels as health care team members with whom people mentally ill have the first contact.[9] However, there is scarcity of mental health professionals, especially nurses in primary care settings including the community level. This gap among health care professionals including mental health nurses at the community level is suggested to have been tackled by community health workers operating very closely with local authorities. Local authorities coordinate all community activities including health related activities as performed by community health workers who are argued to be involved in health care delivery essentially at community settings through coordination of health promotion and preventive interventions. $[10,11]$

Additionally, local authorities are mandated to protect all population from any kind of discrimination and exclusion which are eventually the outcome of stigmatizing attitude. In addition, local authorities are suggested to be close and to be in a good position to assist and doing advocacy of any vulnerable groups including persons with a mental illness within the community. [12] Therefore, local authorities have an important role to play for health care including mental health related services in the community settings. However, current literature suggest stereotyping attitudes towards people with mental illness amongst the general population composed of different categories of people including local authorities as well.[13-15]

At this time when the Rwandan Ministry of Health is integrating mental health services in general health care facilities, especially in the community level, it is argued to be challenged by potential negative stereotypical attitudes amongst local authorities. Also, this could constitute an important barrier to such integration as long as it recommended to start from the community level.

Local and international authors argue that integrated mental health care services from community to central level, will reduce stigmatizing attitudes towards mental illness. $[7,16,17]$ With such integration, anti-stigma initiatives will take place and are suggested to reduce negative stereotypal attitudes in regards to mental illness. Current literature argues that both increased level of contact and knowledge about mental illness are positive mediators of negative stereotypical attitudes towards mental illness. [18,19]
This issue of stigma and anti-stigma initiatives concern health care system in Rwanda and mental health related activities to be integrated in general health care settings. However, there are no studies conducted on stigmatizing attitudes amongst local authorities towards mental health care users in Rwanda. This calls for conducting research in regards to stigmatising attitudes towards people with mental illness amongst different categories of the population in Rwanda. These categories of Rwandan may be directly or indirectly taking part in the integration of mental health services and the process of fight against mental health related stigma.

The aim of this study was to describe stereotypical attitudes among local authorities; and factors linked to negative stereotypical attitudes among local authorities towards persons with mental illnesses

\section{Methods}

\section{Research design}

This study was conducted using quantitative, descriptive design. A self-report questionnaire was used to collect data on the attitudes of local authorities with regard to mental illness. [20,21]

\section{Study setting and participants}

The study was conducted in Muhoza sector in Musanze District in Rwanda. Muhoza sector is composed of 4 cells that are under the responsibility of Executive secretaries and 26 villages under responsibility of and executive committee as led by the chief of village. Local authorities, who participated in this study, are composed of cell executive secretaries (4), cell council members with 10 members for each cell $(4 \times 10=40$ cells council members). Also, the study participants included village executive committees of Muhoza sector with 5 members for each village $(5 \times 26=130$ village executive committee members). Local authorities in Muhoza sector make a total number of 174 .

Muhoza sector was conveniently sampled as it is close to the researcher's work place during his community outreach activities.[20] Villages, cells and local authorities were sampled to obtain sufficient numbers for statistical power in the data analysis that necessitated at least 100 participants.[22] The 174 local authorities operating under Muhoza sector, 123 local authorities were available and accepted to participate in this study that allowed achieving a response rate of $70.6 \%$.

\section{Instruments}

Questionnaire was used to collect data from participants. This tool is composed of three sections: Socialdemographic variables (age, gender, level of education), level of contact scale (LOC) and community attitudes towards persons with mental illness Swedish version (CAMI-S). In this study, participants' socio-demographic factors were considered as independent variables, while 
LOC and CAMI-S were considered as dependant variables. This tool has been adopted from the original level of contact scale (LOC) as developed by Corrigan and his research team in 2001 and the original community attitude towards mental illness Swedish version as developed by Högberg and his colleagues in 2008 in Sweden.[23,24]

The familiarity (level of contact) as developed by Corrigan \& his research group in 2001, is composed of 12 levels from "Never observed a person with mental illness" to "I have mental illness" and was considered as dependant variable.[23] The statement "I have mental illness" is the highest level of familiarity that any person may have in regards to mental illness.[23] The level of contact scale was developed to measure the extent of participants 'familiarity towards persons with mental illness. The tool was previously used by different researchers internationally and locally for example, in Europe by Morris and colleagues (2012), in Nigeria by James and the research team (2012), Adewayu and Maknjuola (2008) and in South Africa by Smith and Middleton (2010).[25-29] Holmes and Colleagues reported the LOC reliability of 0.83.[30]

The community attitude towards mental Illness Swedish version (CAMI-S), has three subscales that make a total of 20 items: open minded and pro-integration subscale ( 9 items); fear and avoidance subscale (6 items); and community mental health ideology subscale (5 items). The community attitude towards mental Illness Swedish version (CAMI-S) was reported by Högberg and his team to have reliability of 0.903 on the 20 items.[24] Both level of contact scale, and community attitude towards Mental Illness- Swedish version were in English and the translation was done from English to Kinyarwanda by translation expert person working in CMHS centre of language enhancement. The translation was done due to the fact that all local authorities do not have ability to express themselves in English, thus local language is highly recommended to be used.

\section{Data collection process}

Before starting the data collection, the researcher held a meeting with the executive secretary of Muhoza sector and it was aiming at agreement on the schedule of data collection according to the planned activities by sector, cells and villages.[20] The researcher collected data from available local authorities and information about the study was given to participants. The participants were found at Muhoza sector headquarters when they were invited for meetings. Regarding the participants who were not available at Muhoza Headquarters, the researcher connected telephonically with cell executive secretaries to facilitate meeting with them at cell headquarters. Participants were given time to ask questions prior to their participation. In addition, before participation, the researcher explained to the participants that participation was voluntary and anonymity was assured. At the end of completion of questionnaires, participants gave them back to the researcher and they were kept in closed envelops.

\section{Data analysis}

The statistical package for social sciences (SPSS) Version 22 was used to analyse data.[22] Regarding the LOC, the highest score from the level of contact was considered because participants were asked to tick on each item applicable to them. The lowest level of contact was scored by 1 and the highest by 10 . To analyse items $4,5,6,10,11,12,13,17$ and 20 on the CAMI -S, scores were reversed. The reverse scoring was performed on respective items because items were expressing negative attitudes towards persons with mental illness. The scale starts by less stigmatizing attitude to more stigmatizing attitude ((strongly agreeing with the statement $($ score $=1)$ agreeing with the statement $($ score $=2)$ neutral $($ score $=3)$, disagreeing with the statement (score=4) and strongly disagreeing with the statement $($ score $=5)$ ). Items $1,2,3,7,8,9,14,15,16,18$ and 19 were not reversed as long as they were positively expressed.

Analysis focused on measures of central tendency and distribution included the range (minimum and maximum), mode (most commonly occurring score), median (the middle score when the score is ranked from smallest to largest and sometimes known as the midpoint), skewness statistics and standard error of skewness statistics and quartiles. The data from items on the CAMI-S was grouped into subscales to compute percentages, proportions, means and standard deviation. Data was not normally distributed as confirmed by measures of central tendency and histograms of each item which revealed a skewed distribution and scores that are clustered to the left side of the distribution.[22] However, non-parametric tests were not used for further analysis due to the fact that the sample was two small (123 participants).[22]

An independent - samples t-test was used to compare the mean score of CAMI-S subscales and total score for males and females (association).[22] One way between groups analysis of variance (Post Hoc Tests) was conducted to test relationship between remaining independent (age, level of education and experience) variables and CAMI-S subscales and total score.[26] The associations were considered statistically significant when the significance level of Levine's tests is $(\mathrm{P}=$ or $<0.05)$.[22] Lastly, correlations were tested by using the Spearman's rho correlation coefficient test. The correlation were tested between level of contact (LOC) and CAMI-S subscales and total score.[26] and it was considered statistically significant, if $\mathrm{p}<.05$ [22]

\section{Ethical considerations}

Before starting the data collection, the ethical approval has been granted to the researcher from the CMHS institutional review board (No 020/CMHS/IRB/2016). [20] Also, a permission to conduct a research was given by the District of Musanze (No 0662/07.04.03) as an administrative structure which supervises all activities of Muhoza sector. The implied consent was used to reduce social desirability bias which is suggested to influence participants' responses. 
In this study, implied consent was used to assure participants of anonymity and attempt to reduce responses that may represent social desirability. The implied consent was considered by the researcher as consent to participate in a study on certain actions of the participant, such as returning a completed questionnaire.[20,21] Local authorities as adult persons were not taken as vulnerable people. Thus this research was argued to be low risk research. There was no remuneration because it is suggested to influence participants' responses and in return biase results. Lastly, the research report was provided to the respective sector and dissemination is in process.[21]

\section{Results}

\section{Study participants characteristics}

Table 1 shows that the total number of participants is 123 composed of females $(n=45 ; 36.6 \%)$ and males $(n=78$; $63.4 \%$ ), while they are distributed into four classes regarding their age; class $1: 18-21(\mathrm{n}=47 ; 30.9 \%)$; class 2 :22-25 ( $\mathrm{n}=41 ; 43.9 \%)$; class $3: 26-30(\mathrm{n}=23 ; 16.3 \%)$ and class 4 : more than $30(n=12 ; 8.9 \%)$. For the distribution of participants according to their level of education, the current study revealed that the majority of local leaders had completed primary school $(n=47 ; 38.2 \%)$, followed by local leaders who had not completed primary school $(\mathrm{n}=41 ; 33.3 \%)$; while local leaders who completed high school (secondary school) were $(n=23 ; 18.7 \%)$ and $(\mathrm{n}=12 ; 9.8 \%)$ have had contact with university studies. The majority of participants were in their first term/ mandate ( $\mathrm{n}=43 ; 35.5 \%)$, while participants with three terms/mandates were $(\mathrm{n}=42 ; 34.1 \%)$ and participants with two terms/mandates were the last with $(n=38$; $30.9 \%$ ).

Table 1. Distribution of participants according to their social-demographic variables

\begin{tabular}{lll}
\hline Sociodemographic variables & Frequency & Percentage \\
\hline 1. Sex of participants & & \\
Female & 45 & $36.6 \%$ \\
Male & 78 & $63.4 \%$ \\
Total & $\mathbf{1 2 3}$ & $\mathbf{1 0 0} \%$ \\
2. Age of participants (in years) & & \\
18-21 & 47 & $30.9 \%$ \\
$22-25$ & 41 & $43.9 \%$ \\
$26-30$ & 23 & $16.3 \%$ \\
Plus 30 & 12 & $8.9 \%$ \\
Total & $\mathbf{1 2 3}$ & $\mathbf{1 0 0} \%$ \\
3. Experience of participants & & \\
(terms) & & \\
First term & 43 & $35.0 \%$ \\
Second term & 38 & $30.9 \%$ \\
Third term & 42 & $34.1 \%$ \\
Total & $\mathbf{1 2 3}$ & $\mathbf{1 0 0} \%$ \\
4. Level of education of & & \\
participants & & \\
Primary school not completed & 47 & $38.2 \%$ \\
Primary school completed & 41 & $33.3 \%$ \\
High school/ Secondary school & 23 & $18.7 \%$ \\
University education & 12 & $9.8 \%$ \\
Total & $\mathbf{1 2 3}$ & $\mathbf{1 0 0} \%$ \\
\hline
\end{tabular}

Results from the community attitudes towards mental illness Swedish version

The community attitudes towards mental illness Swedish version were analyzed using SPSS and percentages were computed to show the number of participants' responses on each Likert-scale and make a total of 100\% for each statement.

As displayed in Table 2, the current study revealed that participants reflected negative stereotypical attitudes on all CAMI-S. These findings indicate that most prevalent negative stereotypical attitudes were on the items 2 \& 7 whereby participants disagree that most persons who were once patients in a mental hospital can be trusted as babysitters $(64.6 \%)$ for item 2 and that mental illness is an illness like any other (64.6\%) for item 7. However, less negative stereotypical attitudes were found on the items 1 \& 8 where participants are for integration of persons with a mental illness by agreeing that residents should accept the location of mental health facilities in their neighborhood to serve the needs of the local community $(71.8 \%)$ for item 1 and that we need to adopt a far more tolerant attitude towards the mentally ill in our society $(71.8 \%)$ for item 8 . There is evidence of contradictions throughout different items on CAMI-S. For example, participants were of the idea that persons with a mental illness could be tolerated and at the same time they agree that mental illness is different from other diseases. This issue of contradictions goes together with neutral positions found on all items but frequently on the item 20 suggesting that people mentally ill should be isolated from the rest of the community $(40.7 \%)$. 


\section{Table 2. Description of participants' responses to statements on the CAMI-S}

\begin{tabular}{|c|c|c|c|c|c|c|}
\hline \multirow[t]{2}{*}{ Item statements } & \multicolumn{6}{|c|}{ Participant responses } \\
\hline & $\begin{array}{l}\text { Strongly } \\
\text { Agree }\end{array}$ & Agree & Neutral & Disagree & $\begin{array}{l}\text { Strongly } \\
\text { Disagree }\end{array}$ & Total \\
\hline
\end{tabular}

Subscale1: Open ended and pro- integration

1. Residents should accept the location of mental health facilities in their neighbourhood to serve the needs of the local community

2. Most persons who were once patients in a mental hospital can be trusted as babysitters

$56(45.5 \%) \quad 33(26.8 \%) 12(9.8 \%) \quad 4(3.3 \%) \quad 18(14.6 \%) \quad 123(100 \%)$

3. Locating mental health services in residential neighbourhoods does not endanger local residents

$\begin{array}{llllll}11(8.9 \%) & \begin{array}{l}18 \\ (14.6 \%)\end{array} & 24(19.5 \%) & 30(24.4 \%) & 40(32.5 \%) & 123(100 \%) \\ 24(19.5 \%) & 44(35.8 \%) & 23(18.7 \%) & 28(22.8 \%) & 4(3.3 \%) & 123(100 \%) \\ 33(26.8 \%) & 37(30.1 \%) & 14(11.4 \%) & 31(25.2 \%) & 8(6.5 \%) & 123(100 \%)\end{array}$

4. Mental health facilities should be kept out of residential neighbourhoods

$$
\text { 33(26.8\%) } 37(30.1 \%) 14(11.4 \%) \quad 31(25.2 \%) \quad 8(6.5 \%) \quad 123(100 \%)
$$

5. Having mental patients living within residential neighbourhoods might be a good therapy, but the risks to the residents are too great

6. Local residents have good reason to resist the location of mental health services in their neighbourhood

$20(16.3 \%) \quad 41(33.3 \%) \quad 30(24.4 \%) \quad 26(21.1 \%) \quad 6(4.9 \%) \quad 123(100 \%)$

$37(30.1 \%) \quad 31(25.2 \%) 25(20.3 \%) \quad 25(20.3 \%) \quad 5(4.1 \%) \quad 123(100 \%)$

7. Mental illness is an illness like any other

$11(8.9 \%) \quad 27(22.0 \%) 8(6.5 \%) \quad 44(37.8 \%) \quad 33(26.8 \%) \quad 123(100 \%)$

8. We need to adopt a far more tolerant attitude towards the mentally ill in our society

$55(44.7 \%) \quad 34(27.6 \%) \quad 11(8.9 \%) \quad 13(10.6 \%) \quad 10(8.1 \%) \quad 123(100 \%)$

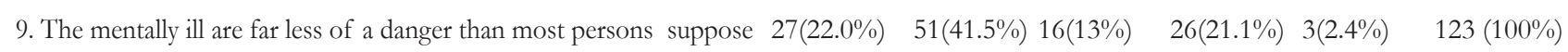

Subscale 2: Fear and avoidance

10. It is best to avoid anyone who has mental problems

$31(25.2 \%) \quad 29(23.6 \%) \quad 15(12.2 \%) \quad 23(18.7 \%) \quad 24(19.5 \%) \quad 123(100 \%)$

11. I would not want to live next door to someone who has been mentally ill

$34(27.6 \%) \quad 30(24.4 \%) \quad 19(15.4 \%) \quad 29(23.6 \%) \quad 11(13.0 \%) \quad 123(100 \%)$

12. It is frightening to think of persons with mental problems living in residential neighbourhoods

$19(15.4 \%) \quad 45(36.6 \%) 9(7.3 \%) \quad 34(27.6 \%) \quad 16(13.0 \%) \quad 123(100 \%)$

13. The best way to handle the mentally ill is to keep them behind locked doors

$43(35.0 \%) \quad 30(24.4 \%) 14(11.4 \%) \quad 20(16.3 \%) \quad 16(13.0 \%) \quad 123(100 \%)$

14. Residents have nothing to fear from persons coming into their neighbourhood to obtain mental health services

$34(27.6 \%) \quad 41(33.3 \%) 19(15.4 \%) \quad 23(18.7 \%) \quad 6(4.9 \%) \quad 123(100 \%)$

Subscale 3: Community mental health ideology

15. Less emphasis should be placed on protecting the public from the mentally ill

$28(22.8 \%) \quad 36(29.3 \%) 27(22.0 \%) \quad 22(17.9 \%) \quad 10(8.1 \%) \quad 123(100 \%)$

16. The best therapy for many mental patients is to be part of a normal community

$37(30.1 \%) \quad 44(35.8 \%) \quad 13(10.6 \%) \quad 17(13.8 \%) \quad 12(9.8 \%) \quad 123(100 \%)$

17. The mentally ill should not be treated as outcasts of society

$54(43.9 \%) \quad 33(26.8 \%) \quad 13(10.6 \%) \quad 8(6.5 \%) \quad 15(12.2 \%) \quad 123(100 \%)$

18. As far as possible, mental health services should be provided through community based facilities

$45(36.6 \%) \quad 34(27.6 \%) \quad 17(13.8 \%) \quad 17(13.8 \%) \quad 10(8.1 \%) \quad 123(100 \%)$

19. No one has the right to exclude the mentally ill from their neighbourhood

$18(14.6 \%) \quad 72(58.5 \%) 25(20.3 \%) \quad 6(4.9 \%) \quad 2(1.6 \%) \quad 123(100 \%)$

20. The mentally ill should be isolated from the rest of the community

$47(38.2 \%) \quad 19(15.4 \%) 50(40.7 \%) \quad 5(4.1 \%) \quad 2(1.6 \%) \quad 123(100 \%)$

Table 3 displays subscales and total scores achieved on the CAMI-S. Measures of central tendency (mean, standard deviation) and distribution indicated more negative attitude towards mental illness on subscale
2 "fear and avoidance" $(M=63.32 ; S D=19.965)$ than subscale 1 "Open minded and pro integration" $(M=$ 53.07; $S D=15.240$ ) and subscale 3 "Community mental health ideology" $(M=37.23 ; S D=12.817)$. 
Table 3. Distribution of subscales and total scores results achieved on community attitude towards mental illness Swedish version

\begin{tabular}{|c|c|c|c|c|c|}
\hline & & $\begin{array}{l}\text { Open minded and pro } \\
\text { integration }\end{array}$ & Fear and avoidance & $\begin{array}{l}\text { Community mental } \\
\text { health ideology }\end{array}$ & Total score \\
\hline \multirow[t]{2}{*}{$\mathrm{N}$} & Valid & 123 & 123 & 123 & 123 \\
\hline & Missing & 0 & 0 & 0 & 0 \\
\hline Mean & & 53.07 & 63.32 & 37.23 & 50.90 \\
\hline Std. Deviation & & 15.240 & 19.965 & 12.817 & 13.521 \\
\hline Skewness & & .232 & .185 & .558 & .228 \\
\hline Minimum & & 22 & 24 & 17 & 24 \\
\hline Maximum & & 91 & 100 & 73 & 81 \\
\hline
\end{tabular}

Significant associations between socio-demographic variables and CAMI- $\mathrm{S}$ subscales and total score

Table 4 displays the associations between sociodemographic variables and the CAMI-S subscales and total score and only significant associations are reported. However, prior to perform any statistical tests, percentages, proportions, mean and standard deviation on CAMI-S subscales and total score were computed. To compare the mean score of CAMI-S subscales and total score for males and females an independent samples t-test was used.[22] The significant difference was considered when the significance level of Levine's tests was $p=.05$ or less. Findings from this study revealed no significant difference on CAMI-S subscales and total scores for female and male participants.

Also, a one-way between groups analysis of variance (Post Hoc Tests) was conducted to explore relationship between independent variables (age, experience and the level of education) and CAMI-S subscales and total score. [22] Comparison of mean scores of CAMI-S subscales for participant groups was computed. These participants groups include; age groups (group 1: 18-21 years; group 2: 22-25 years; group 3: 26-30 years and group 4: 31 years and above), participants' experience groups (group 1: one term, group 2: two terms, group 3: more than 2 terms) and participants level of education groups (group 1: not completed primary school, group 2: completed primary school, group 3: secondary school and group 4: university education). The statistical significance was considered if the $\mathrm{P}$ value is less than or equal to .05.[22]

The Post Hoc Tests found no statistical significance between age groups and score achieved on CAMI-S subscales and the total score. However, a statistically significant difference in CAMI-S subscales and total score for three participants experience (mandate or term) groups was found ((Open minded and pro integration $(F=4.809 ; p=.003) ;$ fear and avoidance $(F=4.479$; $p=.005)$; community mental health ideology $(F=13.536$; $p=.000)$; total score $(F=8.871 ; \mathrm{p}=.000))$. In addition, the statistically significant difference was confirmed by measures of central tendencies (mean and standard deviation as displayed in the Table 4.

The central tendency measures (mean and standard deviation) showed that participants experienced group (who have been elected more than 2 terms), recorded less scores than remaining participants groups (who are working their first and second terms) recording highest scores on the CAMI-S subscales and the total score. The findings indicate that the participants with more experience in local administration system reflected less negative stereotypical attitudes than participants who are less experienced in local administration.

Finally, the Post Hoc Tests revealed statistically significant difference between participants' group education level in regards to CAMI-S subscale 1Open minded and pro integration $(F=6.019 ; \mathrm{p}=.001)$ and the total score $(F=5.720 ; \mathrm{p}=.001)$ for four level of education participants groups. Also, the statistical difference was confirmed by measures of central tendencies (mean and standard deviation) as displayed in Table 4. The statistical difference suggested that participants with high level of education (university and secondary) recorded lower score on open minded and pro-integration subscale and the total score than participants with lower education (the group who did not completed primary education and the group that completed primary education) who recorded higher scores. This difference indicates that participants with high level of education reflected less negative stereotypical attitudes towards people with mental illness than participants with lower level of education. 
Table 4. Significant associations between socio-demographic variables and community attitude towards mental illness subscales and the total score

\begin{tabular}{|c|c|c|c|c|c|}
\hline & & $\begin{array}{l}\text { Open minded and } \\
\text { pro integration }\end{array}$ & $\begin{array}{l}\text { Fear and } \\
\text { avoidance }\end{array}$ & $\begin{array}{l}\text { Community mental } \\
\text { health ideology }\end{array}$ & Total score \\
\hline \multicolumn{6}{|l|}{ Associations } \\
\hline \multicolumn{6}{|l|}{ Education } \\
\hline \multirow[t]{4}{*}{ Mean } & No primary education & 56.02 & 66.81 & 37.85 & 53.30 \\
\hline & Primary education & 50.02 & 60.20 & 34.63 & 47.98 \\
\hline & Secondary education & 59.30 & 69.74 & 42.35 & 56.83 \\
\hline & University & 40.00 & 48.00 & 33.83 & 40.17 \\
\hline \multirow[t]{4}{*}{ SD } & No primary education & 14.768 & 19.470 & 13.955 & 13.691 \\
\hline & Primary education & 15.413 & 20.238 & 12.955 & 13.630 \\
\hline & Secondary education & 13.656 & 17.091 & 10.870 & 10.434 \\
\hline & University & 9.391 & 18.211 & 8.178 & 9.750 \\
\hline $\mathrm{F}$ & & 6.019 & 4.280 & 2.161 & 5.720 \\
\hline $\mathrm{p}$ & & .001 & .007 & .097 & .001 \\
\hline \multicolumn{6}{|l|}{ Experience } \\
\hline \multirow[t]{3}{*}{ Mean } & 1 term $/$ mandate & 56.81 & 69.33 & 44.25 & 56.19 \\
\hline & 2 terms / mandates & 53.19 & 62.21 & 36.17 & 50.36 \\
\hline & $\begin{array}{l}3 \text { terms / mandates and } \\
\text { more }\end{array}$ & 49.58 & 59.20 & 36.17 & 50.36 \\
\hline \multirow[t]{3}{*}{ SD } & $1 \mathrm{term} /$ mandate & 17.903 & 19.759 & 13.580 & 14.764 \\
\hline & 2 terms / mandates & 14.981 & 21.310 & 13.578 & 13.857 \\
\hline & $\begin{array}{l}3 \text { terms/ mandates and } \\
\text { more }\end{array}$ & 12.199 & 17.569 & 7.591 & 10.302 \\
\hline $\mathrm{F}$ & & 4.809 & 4.479 & 13.536 & 8.571 \\
\hline $\mathrm{p}$ & & .003 & .005 & .000 & .000 \\
\hline
\end{tabular}

Correlation between the level of contact and community attitudes towards mental illness

As described in the section of instruments, the level of contact scale ranges between a score of 1 "Never observed a person with mental illness" and a score of 12 , "I have a mental illness". [23] In this study, the findings revealed that the level of contact score was ranged between score of 1 "Observed a person with mental illness in passing $(0.6 \%, \mathrm{n}=1)$ and score of 12 , I have a mental illness $(7 \%, \mathrm{n}=11)$. The common occurring score was level 8 , providing services or assistance to persons with mental illness ( $\mathrm{n}=22 ; 17.9 \%$ ) while the less commonly occurring score was level 2, Observed in passing a person with mental illness ( $\mathrm{n}=1$; $0.8 \%$ ). However, no one among participants responded to ever have observed a person mental illness $(\mathrm{n}=0 ; 0 \%)$. To measure the level of contact, participants were asked to tick on each statement where it was applicable and the highest level was considered by the researcher.

A Spearman's rho correlation coefficient was performed for testing correlation between the participants level of contact and score achieved on the community attitude towards mental illness- Swedish version, subscales (subscale 1; open minded and pro integration, subscale 2; fear and avoidance and subscale 3; community mental health ideology); and the total score.[22]
Statistical significance was considered if $\mathrm{p}<.05$ and only significant correlation is reported.[22] The spearman's rho correlation coefficient revealed negative correlation (rho $=-.498 ; \mathrm{p}=.000$ ) between participants level of contact and subscale 1 (open minded and prointegration). Also, negative correlation (rho $=-.339$; $\mathrm{p}=.000)$ was found between the level of contact and the subscale 2 (fear and avoidance); between the level of contact and the subscale 3 (community mental health ideology $(\mathrm{rho}=-.430 ; \mathrm{p}=.000)$ ) and the total score (rho=$.522 ; \mathrm{p}=.000)$. The negative correlation indicates that increase in level of contact correlates with a decrease in score achieved on the CAMI-S subscales (open minded and pro-integration, fear and avoidance and community mental health ideology) and the total score.

\section{Discussion}

The current study revealed negative stereotypical attitudes among local authorities towards people with mental illness. This study revealed similar findings from studies conducted internationally like European countries in 2012 by Morris and colleagues who found stigmatizing attitudes among students and Rosemberg in United Kingdom- London in 2018, who found stigmatising attitudes towards persons with mental illness among general population.[29,31] Bennett and 
colleagues in Jamaica (2015) conducted a study that revealed negative stereotypical attitudes among nursing students towards persons with mental illness and in Poland, Kopera and his research team conducted a study that revealed negative stereotypical attitudes among both mental health professionals and students in 2015.[32,33] Also, findings from the current studies are in line with local studies conducted in Africa that revealed negative stereotypical attitudes among research participants towards persons with a mental illness. For example, a study conducted by Kapungwe and colleagues in Zambia revealed negative stereotypical attitudes among primary health care providers towards persons with a mental illness, while Barke and his colleagues in Ghana found stigmatizing attitudes among the population in regards to mental illness. $[14,16]$

However, participants agree with the idea of placement of mental health care services within the communities while they expressed a need of social distance with persons mentally ill. This was evidenced by several contradictions and neutral positions used to be taken by research participants.

In addition to these contradictions, the findings of the current study revealed neutral positions that are argued to be the result of social desirability bias. [33,34] Here, participants seem to agree with the declaration of United Nations (UN) about human rights and this issue of human rights has been taken into consideration in the costitution of different countries. The Rwandan constitution stipulates that all Rwandese are equal and must be given equal opportunities and be protected from any kind of exclusion or segregation.[12,35]

The current study revealed an association between the experience of participants in regards to local administration system (in regards to numbers of terms / mandate) and the level of education and scores achieved on the CAMI-S subscales and the total score. These findings are in line with findings from the studies conducted by Barke and colleagues in Ghana (2011) among the general public and Song and colleagues in Taiwan (2005) among general public which revealed an association between the level of education and negative attitudes towards people mentally ill.[14,36] In addition, a study conducted in western Nigerian in 2008 by Adewaya and Oguntande found an association between experience and attitude towards people mentally ill.[27] Bjorkman and colleagues (2008) in Sweden, found an association between experience and stigmatizing attitude towards persons with mental illness among nursing staff. [37]

However, the current study revealed no significant association between sex and age of participants and the scores achieved on the CAMI-S subscales and the total score. This is consistent with a study conducted among mental health professionals and medical students by Kopera and colleagues in Poland suggesting no significant difference between females and males. [33]

Finally, participants in the current study reported a high level of contact with persons with mental disorders. The study results revealed a negative correlation between familiarity and negative stereotypical attitudes suggesting a mediating relationship between familiarity with persons with mental illness. In other words, decreased negative stereotypes were associated with increased familiarity.

These results are consistent with findings reported in literature from studies carried out on both the general population and health care professionals, suggesting a significant negative correlation between familiarity and stigmatizing attitudes.[23,29,30] These authors suggest that individuals who have a relative or a friend with a mental illness do not generally perceive mentally ill persons as being dangerous and therefore desire less social distance from them.

The study conducted by Adewayu and Maknjuola (2008) on social distance towards people with mental illness in South Western Nigeria suggested that high social distance towards people with mental illness correlates with having never cared for someone who is mentally ill. However, findings from this study contrast with other previous studies that have been conducted in Africa. For example, the study conducted by Smith and Middleton (2010), in South Africa, included a representative sample of potential employers who had high levels of intimate contact with persons with serious mental illnesses, and reported evidence of no relationship between familiarity and the extent of negative stereotyping or desire for social distance.[28] Also, findings from a study conducted by James and colleagues (2012) in Southern Nigeria on stigmatizing attitudes held by medical students and interns towards persons with mental illnesses suggested no significant correlation between familiarity with mental illness and stigmatizing attitudes.[26]

\section{Conclusion}

The current study revealed negative stereotypical attitudes among local authorities in regards to persons with mental illness in Muhoza sector. Also, findings from this study showed important contradictions and neutral responses. This study revealed significant association between participants experience and level of education and CAMI-S subscales (open minded and prointegration, fear and avoidance and community mental health ideology subscales) and total scores. Finally, results from this study showed that participants' level of contact correlates with CAMI-S subscales (open minded and pro-integration, fear and avoidance and community mental health ideology subscales) and the total scores. To clarify contradictions and neutral position found 
among local authorities, more studies especially interventional research, are recommended to be extended to the whole country. These studies are aiming at providing national empirical data on attitudes towards people mentally ill and will analyse deeply the effectiveness of familiarity with people mentally ill in the process of reducing the negative stereotypical attitudes associated with mental illnesses.

To reduce negative stereotypical attitudes among local authorities' different activities happening at the villages could help to increase their level of knowledge in regards to mental health. These activities might include discussions or public talks about mental illness and can be organized at village level whereby all categories of people living in the village could benefit from them. Also, mental illness could be recommended among topics which are taught during the local leaders gathering commonly called ITORERO to improve knowledge in regards to mental illness.

Persons with mental illness could provide testimonies to increase the familiarity towards mental illness among local authorities and the general population that will reduce the negative stereotypes towards people mentally ill.

Two limitations for the current study are to be mentioned and these include the impossibility to generalize findings to all local authorities in the district or in Rwanda because the study was conducted in one selected sector. Also, the presence of the researcher on the research setting during the data collection would have been affecting the participants' responses.[20] In addition, the researcher used implied consent by submission of questionnaire, instead of informed consent. This was to reduce possible discomfort among participants and show evidence of voluntary participation and for reducing social desirability bias.[21]

\section{Acknowledgement}

Authors address thanks to the District of Musanze which offered a permission to conduct this study. Also, acknowledgement to the CMHS/ institutional review board that provided ethical clearance approving the study to be conducted.

\section{Conflict of interest}

The authors declare that there is no competing interest

\section{Contribution of authors}

VB was involved in conceptual design, empirical analysis and dissemination phases. While AG and FU participated in data analysis and manuscript revision.

This article is published open access under the Creative Commons Attribution-NonCommercial NoDerivatives (CC BY-NC-ND4.0). People can copy and redistribute the article only for noncommercial purposes and as long as they give appropriate credit to the authors. They cannot distribute any modified material obtained by remixing, transforming or building upon this article. See https://creativecommons.org/ licenses/by-nc-nd/4.0/

\section{References}

1. Association AP. Diagnistic and Statistacal Manuel of Mental Disorder. 5th ed. Washington DC: American Psychiatric Publishing; 2013.

2. World Health Organization. The WHO Mental Atlas 2011 [Internet]. World Heal. Organ. 2011. Available from: http://whqlibdoc.who.int/ publications/2011/9799241564359_eng.pdf

3. Mckimm, D, \& Nicholson J. Global health. Rondon: Sage; 2015.

4. Clement S, Schauman O, Graham T, Maggioni F, Evans-Lacko S, Bezborodovs N, et al. What is the impact of mental health-related stigma on helpseeking? A systematic review of quantitative and qualitative studies. Psychol. Med. 2015. p. 11-27.

5. World Health Organisation. Comprehensive mental health action plan 2013-2020. Geneva 66th World Heal Assem [Internet]. 2013;1-27. Available from: http:// scholar.google.com/scholar?hl=en\&btnG= Search\&q=intitle:Comprehensive + mental + health + action + plan $+2013+?+2020 \# 0$

6. Rwandan Ministry of Health. Mental Health Policy in Rwanda. Rwanda; 2011.

7. Ssebunnya J, Kigozi F, Kizza D, Ndyanabangi S. Integration of Mental Health into Primary Health Care in a rural district in Uganda. Afr J Psychiatry. 2010;13:128-31.

8. Lund C, Kleintjes S, Kakuma R, Flisher AJ, Consortium MhRP. Public sector mental health systems in South Africa: inter-provincial comparisons and policy implications. Soc Psychiatry Psychiatr Epidemiol. 2010;45:393-404.

9. Rwandan Ministry of Health. Health sector strategic plan 2009-2012. Rwanda; 2009 p. 33.

10. Rwandan Governement. Making Decentralized Service Delivery Work: Putting the people at the center of service provision. Kigali; 2006.

11. Rwandan Governement. Governance and decentralization joint sector review. Kigali, Rwanda; 2017.

12. Republic of Rwanda. Constitution of Rwanda. Rwanda; 2016. 
13. Vedaste B, Smith AAH. 'In principle, yes, in application, no': Rwandan nurses' support for integration of mental health services. African J Nurs Midwifery. 2016;18:170-82.

14. Barke A, Nyarko S, Klecha D. The stigma of mental illness in Southern Ghana: Attitudes of the urban population and patients' views. Soc Psychiatry Psychiatr Epidemiol. 2011;46:1191-202.

15. Vedaste B. Students Nurses stigmatizing attitudes towards persons with a mental disorder in a selected school of nursing in Rwanda. Rwanda J Med Heal Sci. 2017;4:1-7.

16. Kapungwe A, Cooper S, Mayeya J, Mwanza J, Mwape L, Sikwese A, et al. Attitudes of primary health care providers towards people with mental illness: evidence from two districts in Zambia. Afr J Psychiatry [Internet]. 2011;14. Available from: http://www.ajol.info/index.php/ajpsy/article/ view/70284

17. Mwape L, Sikwese A, Kapungwe A, Mwanza J, Flisher A, Lund C, et al. Integrating mental health into primary health care in Zambia: A care provider's perspective. Int J Ment Health Syst. 2010;4.

18. Corrigan PW, Powell KJ, Fokuo JK, Kosyluk KA. Does humor influence the stigma of mental illnesses? J Nerv Ment Dis. 2014;202:397-401.

19. Corrigan PW, Mittal D, Reaves CM, Haynes TF, Han X, Morris S, et al. Mental health stigma and primary health care decisions. Psychiatry Res. 2014;218:35-8.

20. Maree K. First steps in Research. 1st ed. Pretoria: Van Schaik.; 2008.

21. Polit, D F, \& Beck CT. Nursing research: Generating and Assessing Evidence for Nursing Practice. 9th ed. Philadelphia: Wolters Kluwer Health/ Lippincott Williams and Wilkins; 2012.

22. Pallant I. SPSS survival manual. 5th ed. Berkshire, England: Open University Publishers.; 2013.

23. Corrigan PW, Edwards AB, Green A, Diwan SL, Penn DL. Prejudice, Social Distance, and Familiarity with Mental Illness. Schizophr Bull. 2001;27:21925.

24. Högberg T, Magnusson A, Ewertzon M, Lützén K. Attitudes towards mental illness in Sweden: Adaptation and development of the community attitudes towards mental illness questionnaire. Int J Ment Health Nurs. 2008;17:302-10.

25. Björkman T, Angelman T, Jönsson M. Attitudes towards people with mental illness: A crosssectional study among nursing staff in psychiatric and somatic care. Scand J Caring Sci. 2008;22:170-7.

26. James BO, Omoaregba JO, Okogbenin EO. Stigmatising attitudes towards persons with mental illness: A survey of medical students and interns from Southern Nigeria. Ment Illn. 2012;4:32-4.

27. Adewayu, A O, \& Maknjuola ROA. No TitleLay belief regarding causes of mental illness in Nigeria, pattern and correlates. Soc Psychiatry Psychiatr Epidemiol. 2008;43:336-41.

28. Smith, A A H, \& Middleton LE. No TitleThe effect of familiarity on stigma components in potential employers towards people with a serious mental illness in Durban KwaZulu Natal. Univ KwaZuluNatal Publ. 2010;

29. Morris R, Scott PA, Cocoman A, Chambers M, Guise V, Välimäki M, et al. Is the Community Attitudes towards the Mentally Ill scale valid for use in the investigation of European nurses' attitudes towards the mentally ill? A confirmatory factor analytic approach. J Adv Nurs. 2012;68:460-70.

30. Holmes EP, Corrigan PW, Williams P, Canar J, Kubiak MA. Changing attitudes about schizophrenia. Schizophr Bull. 1999;25:447-56.

31. Rosenberg S.J. \& Rosenberg. J. Community mental health: Challenges for the 21st Century. 3rd ed. London: Routledge; 2018.

32. Bennett J, Stennett R. Attitudes towards mental illness of nursing students in a Baccalaureate programme in Jamaica: A questionnaire survey. J Psychiatr Ment Health Nurs. 2015;22:599-605.

33. Kopera M, Suszek H, Bonar E, Myszka M, Gmaj B, Ilgen M, et al. Evaluating Explicit and Implicit Stigma of Mental Illness in Mental Health Professionals and Medical Students. Community Ment Health J. 2015;51:628-34.

34. Putman S. Mental illness: Diagnostic title or derogatory term? (Attitudes towards mental illness) Developing a learning resource for use within a clinical call centre. A systematic literature review on attitudes towards mental illness. J Psychiatr Ment Health Nurs. 2008;15:684-93.

35. United Nations. Universal Declaration of Human Rights. USA; 1995.

36. Song, L, Chang, L, Yi, C, Shih, Yuan, C, Lin \& Y. No TitleCommunity attitudes towards the mentally ill: The results of a national survey of the taiwanese population. Int J Soc Psychiatry. 2005;51:174-88.

37. Björkman T, Angelman T, Jönsson M. Attitudes towards people with mental illness: a crosssectional study among nursing staff in psychiatric and somatic care. Scand J Caring Sci [Internet]. 2008;22:170-7. Available from: http://search. ebscohost.com/login.aspx?direct $=$ true $\& \mathrm{db}=\mathrm{c} 8 \mathrm{~h} \&$ $\mathrm{AN}=2010020157 \&$ site $=$ ehost-live \&scope $=$ site 